\title{
A Behavioral Maturity Model to Establish Knowledge Management in an Organization
}

\author{
Camellia Salehi Fashami \\ Department of Information Technology Management \\ College of Management and Economics \\ Science and Research Branch, Islamic Azad University \\ Tehran, Iran
}

\author{
Mohammadreza Babaei \\ Department of Industrial Management \\ College of Management and Accounting \\ Yadegar-e-Imam Khomeini (RAH) ShahreRey Branch \\ Islamic Azad University \\ Tehran, Iran
}

\begin{abstract}
Modern organizations need intangible assets such as organizational knowledge and human resources to gain competitive advantage in the market. Organizations can provide opportunities for behavioral maturity of managers to establish knowledge management. This study tries to develop a behavioral maturity model for managements to examine effectiveness of knowledge management. The study is conducted in Iran Insurance Company as an empirical case study. Twenty academic and organizational experts are selected for the study. Employees and managers of Iran Insurance Company are used to measure and test conceptual model (behavioral maturity of managers to establish knowledge management). Both interview and questionnaire tools are used to collect data. Fuzzy AHP and PLS methods are used to analyze the collected data. Fuzzy AHP results show that transformational leadership, human and social skills, knowledge orientation, emotional intelligence, trustful climate are identified as highly effective priorities.
\end{abstract}

Keywords-behavioral maturity model; knowledge management; managers; organization

\section{INTRODUCTION}

Knowledge organization is considered one of the organizational capitals. Organizational knowledge means choosing the right science in the appropriate time and conditions [1]. In fact, information and knowledge management has become a strong position to survive in dynamic and innovative organizations; even market and business competitiveness requires acquisition, development and updating of individual and organizational knowledge to the extent that knowledge is considered as an essential part of organizational capitals [2]. Hence, intelligent management is to use knowledge to face and deal with uncertainty factors, maintain opportunities and innovate to expand competition [3]. This requires organizations to value and prioritize knowledge management and related steps as an essential requirement for pioneering in the competition [4]. Organizations with a high degree of creativity and work performance manage their knowledge more effectively [5]. In current business environment which is characterized by market globalization, increased competition and high rate of technological changes, tangible assets (such as capital, land, raw materials, etc.) do not create sustainable competitive advantages for the organization. Recognition of knowledge management as the spirit of organizational actions is essential for its implementation [6]. Despite strong reasons for strategic use of knowledge management to improve organizational performance, there are various obstacles in implementing knowledge management in organizations [7]. These obstacles can be summarized as: 1) unfamiliarity of managers with knowledge management (senior and middle managers are not fully familiar with knowledge management and do not understand its advantages for the organization); 2) employees consider knowledge as a source of power (employees do not tend to share their knowledge) [7].

Currently, managers realize that machinery, equipment and buildings are not the most important organizational assets and and that a proper management of organizational knowledge lead to a competitive advantage for the organization [8]. Following significance of knowledge assets, organizations are increasingly required to manage their knowledge assets. Organizations need to share organizational knowledge between different sectors to accelerate individual and organizational performance [9]. It seems essential that leadership establish knowledge in the organization properly. Considering the essential role of knowledge management, numerous methods have been presented for deployment of knowledge management in the organization; this confuses managers who tend to implement knowledge management. The purpose of this study is to develop a behavioral maturity model of managers for effectiveness of knowledge management establishment in Iran Insurance Company.

\section{LITERATURE REVIEW}

In [10], authors identified the effective factors on establishment of knowledge management systems in Taiwanese SMEs. They used LISREL to analyze the data gathered. Factor analysis model showed that structural (organizational), infrastructural and human factors were very important and effective in establishing knowledge management systems. In [11], authors developed a model for effective factors on establishment of knowledge management. Their findings showed that employee participation and organizational 
factors including culture had the highest effect on successful establishment of knowledge management. In [12], authors experimentally evaluated knowledge sharing, knowledge leakage and innovative performance. Their results indicated that knowledge sharing positively influenced innovative performance; however, high rate of knowledge leakage negatively moderated the relationship between knowledge sharing and innovative performance. In [13], authors examined the role of knowledge-based leadership on actions of knowledge management and innovation. They found that actions of knowledge management mediated the relationship between knowledge-based leadership and innovative performance. Moreover, they found that actions of knowledge management were effective on innovative performance. In [14], authors addressed the barriers and solutions of knowledge management establishment in Iranian public organizations. They noted that intellectual assets and knowledge are as important as other physical and financial assets. They considered human, technological and structural barriers as important barriers to establishment of knowledge management. Moreover, their solutions included the increased leadership support, promoted learning and restructure of organizations. In [15], authors studied the infrastructures required for establishing knowledge management in universities. As they noted, knowledge management was considered as a strategic need of education and higher education institutions in the third millennium. In [16] the effect of knowledge management establishment on organizational excellence was determined. It was noted that proper knowledge management leads to competitive advantage and ultimately organizational excellence. The study was conducted in Payam Nour University of West Azarbaijan using descriptive-survey approach. Considering the great responsibility of Payam Nour University, it has established knowledge management in the organizational structure through a knowledge network including top and middle management, executives and employees. Collaboration, learning culture and knowledge sharing has improved capabilities of employees; it is suggested to repeat this study in other organizations. In [17], authors concluded that knowledge management directly influenced organizational innovation in manufacturing firms. In [18], authors analyzed the effect knowledge management project and EFQM for improving the key results of the business. In [19], authors defined a model to properly evaluate knowledge management value.

\section{RESEARCH METHODOLOGY}

The participants in this study included 20 experts in knowledge management establishment and organizational behavior as well as 800 employees of Iran Insurance Company. Twenty experts were used to identify effective factors on the role of behavioral maturity model in establishing knowledge management in the Iran Insurance Company. A series of criteria were determined for inclusion of experts; these criteria included practical and working experience, major and important positions in the company, enough experience in establishing knowledge management, and at least a bachelor's degree. Based on Cochran's formula, at least 260 questionnaires should be handed out, however, in an effort to increase the validity of the study, a total of 280 questionnaires were distributed.

\section{A. Fuzzy Analytic Hierarchy Process (AHP)}

Triangular fuzzy numbers are used to avoid ambiguity caused by uncertainty in decision-making. Table I shows pairwise comparisons in AHP. A triangular fuzzy number denoted by $\tilde{\mathrm{A}}=(1, \mathrm{~m}, \mathrm{u})$ has the following membership function. Figure 1 shows the membership function selected for fuzzy numbers. Two indexes are used for triangular fuzzy numbers: confidence and optimism. Confidence index $(\alpha)$ indicates confidence of the decision maker in his prioritization and judgement. By defining $\alpha$, triangular fuzzy number is defined as follows:

$$
\begin{aligned}
& \mu_{F}(x)= \begin{cases}0, & x<1 \\
x-1 / m-1, & 1 \leq x \leq m \\
u-x / u-m, & m \leq x \leq u \\
0, & x>u\end{cases} \\
& \forall_{\alpha} \in[0,1] M_{\alpha}=\left[l^{\alpha}, u^{\alpha}\right]=[(m-1) \alpha+1,-(u-m) \alpha+u]
\end{aligned}
$$

Optimism index $(\mu)$ can be used to estimate success rate. Optimism index as shown in the formula (3) is a linear convex combination.

$$
a_{i j}^{-\alpha}=\mu a_{i j u}^{\alpha}+(1-\mu) a_{i j u}^{\alpha}, \quad \forall_{\mu} \in[0,1]
$$

Accordingly, the following matrix can be formed from pairwise comparisons.

$$
\tilde{A}=\left[\begin{array}{lcccc}
1 & \tilde{a}_{12}^{\alpha} & \cdots & \cdots & \tilde{a}_{1 n}^{\alpha} \\
\tilde{a}_{21}^{\alpha} & 1 & \cdots & \cdots & \tilde{a}_{2 n}^{a} \\
\vdots & \vdots & \vdots & \vdots & \vdots \\
\tilde{a}_{n 1}^{\alpha} & \tilde{a}_{n 2}^{\alpha} & \cdots & \cdots & 1
\end{array}\right]
$$

By completing pairwise comparisons, weight vector of indexes is calculated by using the following formula where $\lambda_{\max }$ is the largest eigenvalue of the matrix:

$$
A w=\lambda_{\max } w
$$

Once all matrices of pairwise comparisons are formed, consistency rate $(\mathrm{CR})$ is calculated for each matrix using the following formula:

$$
C R=\frac{C I}{R I}
$$

CI indicates deviation from consistency and is calculated by:

$$
C I=\frac{\lambda_{\max }-n}{n-1}
$$

where, $\mathrm{n}$ denotes the size of pairwise comparisons matrix and RI represents random consistency index or average weights produced randomly, which can be extracted from the relevant Table 1 . $\mathrm{CR}<0.01$ indicates acceptable comparisons; otherwise, 
comparisons should be repeated with more accurate information by more experienced people.

\section{MEASUREMENT MODEL EVALUATION}

Convergent validity and discriminant validity are used to evaluate reliability of the measurement model using confirmatory factor analysis (CFA) and average variance extracted (AVE). CFA is in fact an extension of ordinary factor analysis and an important aspect of structural equations in which certain hypotheses are tested on the structure of factor loadings. According to [20], factor loadings which are larger than 0.5 are acceptably valid. Moreover, $\mathrm{AVE} \geq 0.5$ is acceptable. As shown in Table I, all factor loadings are at least 0.5 ; thus, convergent validity of data is fully confirmed. Moreover, t-values listed in the left column indicate effectiveness of this variable for its corresponding construct. $\mathrm{T}$ values $\geq 1.96$ indicate that the variable is effective for the considered construct at $95 \%$ confidence interval; otherwise, the variable is not effective. Obviously, t-values are $>1.96$ for all variables, indicating their effectiveness on the corresponding construct. Therefore, convergent validity of the constructs is confirmed. Moreover, composite reliability and Cronbach's alpha obtained for all constructs indicate acceptable internal consistency of the measurement models.

\section{FINDING AND RESULTS}

Following criteria were extracted for the evaluation of behavioral maturity (Table II). These criteria were confirmed by experts and professors for their effect on behavioral maturity of managers for establishment of knowledge management. The second questionnaire developed as a matrix of these variables was distributed among experts.

\section{A. Prioritization of Criteria Using Fuzzy AHP}

Since 20 experts were used in this study, there are 20 different matrixes for comparison of criteria. Fuzzy AHP initially converts these matrixes to a single matrix. Let $\mathrm{a}^{\mathrm{k}} \mathrm{ij}$ be the element related to the k-th respondent for comparison of the criterion $\mathrm{i}$ with criterion $\mathrm{j}$; geometric mean for corresponding elements is calculated by:

$$
\tilde{a}_{j}=\left(\prod_{k=1}^{n} k^{k}\right)^{\frac{1}{n}}
$$

$$
\tilde{a}_{j}=\left(\tilde{a}_{j}^{1} \otimes \tilde{a}_{j}^{2} \otimes . . \otimes \tilde{a}_{j j}^{10}\right)^{\frac{1}{10}}
$$

$\tilde{a}_{12}=((1,23) \otimes(1,1,1) \otimes(1.67,0.20 .25) \otimes(4,5,6) \otimes(2,3,4) \otimes(0.20 .33,0.5) \otimes(6,7,8) \otimes(2,3,4) \otimes(1,2,3) \otimes(2,3,4))^{\frac{1}{10}}=$ $(1.23,1.73,226)$

\section{B. Calculation of Fuzzy Weights for Behavioral Maturity Criteria}

Considering fuzzy AHP, information of the integrated matrix of criteria is analyzed as follows. First, geometric mean of value of the $\mathrm{j}$-th criterion is determined to other criteria:

$\tilde{r}_{1}=\left(\tilde{a}_{11} \otimes \tilde{a}_{12} \otimes \tilde{a}_{13} \otimes \tilde{a}_{14} \otimes \tilde{a}_{15} \otimes \tilde{a}_{16} \otimes \tilde{a}_{17} \otimes \tilde{a}_{18} \otimes \tilde{a}_{19} \otimes \tilde{a}_{110} \otimes \tilde{a}_{111} \otimes \tilde{a}_{112} \otimes \tilde{a}_{13}\right)^{\frac{1}{13}}$

For example, value of the first criterion is calculated as follows:

\begin{tabular}{|c|c|c|c|c|c|c|}
\hline Constructs & Item & $\begin{array}{l}\text { Factor } \\
\text { loading }\end{array}$ & $\begin{array}{c}\mathrm{t}- \\
\text { statistic }\end{array}$ & AVE & $\mathrm{CR}$ & $\begin{array}{c}\text { Cronbach's } \\
\alpha\end{array}$ \\
\hline \multirow{3}{*}{$\begin{array}{c}\text { Personnel } \\
\text { empowerment }\end{array}$} & 2 & 0.862 & 26.348 & \multirow{3}{*}{0.665} & \multirow{3}{*}{0.855} & \multirow{3}{*}{0.747} \\
\hline & 3 & 0.833 & 17.926 & & & \\
\hline & 1 & 0.749 & 13.226 & & & \\
\hline \multirow{3}{*}{$\begin{array}{l}\text { Training courses } \\
\text { for managers }\end{array}$} & 4 & 0.905 & 40.111 & \multirow{3}{*}{0.813} & \multirow{3}{*}{0.929} & \multirow{3}{*}{0.885} \\
\hline & 6 & 0.904 & 32.683 & & & \\
\hline & 5 & 0.897 & 40.228 & & & \\
\hline \multirow{3}{*}{ Teamwork spirit } & 8 & 0.869 & 22.148 & \multirow{3}{*}{0.754} & \multirow{3}{*}{0.902} & \multirow{3}{*}{0.838} \\
\hline & 7 & 0.876 & 31.277 & & & \\
\hline & 9 & 0.861 & 22.938 & & & \\
\hline \multirow{3}{*}{$\begin{array}{l}\text { Decision-making } \\
\text { power }\end{array}$} & 10 & 0.931 & 70.387 & \multirow{3}{*}{0.773} & \multirow{3}{*}{0.902} & \multirow{3}{*}{0.838} \\
\hline & 12 & 0.887 & 36.741 & & & \\
\hline & 11 & 0.816 & 17.972 & & & \\
\hline \multirow{3}{*}{$\begin{array}{l}\text { Human and } \\
\text { social skills }\end{array}$} & 15 & 0.929 & 64.505 & \multirow{3}{*}{0.822} & \multirow{3}{*}{0.932} & \multirow{3}{*}{0.892} \\
\hline & 14 & 901 & 55.742 & & & \\
\hline & 13 & 0.884 & 31.577 & & & \\
\hline \multirow{3}{*}{ Trustful climate } & 17 & 0.898 & 47.325 & \multirow{3}{*}{0.729} & \multirow{3}{*}{0.889} & \multirow{3}{*}{0.813} \\
\hline & 18 & 0.857 & 26.824 & & & \\
\hline & 16 & 0.804 & 12.578 & & & \\
\hline \multirow{3}{*}{$\begin{array}{l}\text { Professional } \\
\text { commitment and } \\
\text { responsibility }\end{array}$} & 21 & 0.871 & 13.004 & \multirow{3}{*}{0.633} & & \\
\hline & 20 & 0.798 & 8.814 & & 0.837 & 0.714 \\
\hline & 19 & 0.711 & 10.524 & & & \\
\hline Knowledge & 22 & 0.897 & 28.144 & & & \\
\hline orientation and & 23 & 0.879 & 29.775 & 0.775 & 0.912 & 0.856 \\
\hline $\begin{array}{l}\text { organizational } \\
\text { knowledge }\end{array}$ & 24 & 0.867 & 28.803 & & & \\
\hline & 26 & 0.948 & 85.920 & & & \\
\hline Quantitative & 27 & 0.885 & 27.977 & 0.820 & 0.932 & 0.890 \\
\hline & 25 & 0.884 & 28.201 & & & \\
\hline & 29 & 0.898 & 25.511 & & & \\
\hline Supportive & 30 & 0.872 & 22.505 & 0.770 & 0.909 & 0.851 \\
\hline & 28 & 0.863 & 27.600 & & & \\
\hline & 31 & 0.867 & 15.689 & & & \\
\hline Iransformational & 32 & 0.855 & 21.862 & 0.737 & 0.893 & 0.824 \\
\hline & 33 & 0.854 & 25.956 & & & \\
\hline & 34 & 0.890 & 26.452 & & & \\
\hline $\begin{array}{l}\text { Emotional } \\
\text { Intelligence }\end{array}$ & 36 & 866 & 30.496 & 0.740 & 0.895 & 0.825 \\
\hline & 35 & 0.825 & 18.827 & & & \\
\hline & 38 & 0.840 & 14.796 & & & \\
\hline Motivation & 37 & 0.760 & 7.659 & 0.571 & 0.798 & 0.814 \\
\hline & 39 & 0.657 & 6.128 & & & \\
\hline
\end{tabular}

TABLE I. FACTOR LOADINGS OF THE OBSERVED VARIABLES

TABLE II. EFFECTIVE CRITERIA ON BEHAVIORAL MATURITY OF MANAGERS EXTRACTED FROM LITERATURE AND INTERVIEWS

\begin{tabular}{|c|c|}
\hline Criteria & Symbol \\
\hline Transformational leadership & $\mathrm{C} 1$ \\
\hline Emotional intelligence of managers & $\mathrm{C} 2$ \\
\hline Training courses for managers & $\mathrm{C} 3$ \\
\hline Knowledge orientation and organizational knowledge & $\mathrm{C} 4$ \\
\hline Quantitative management & $\mathrm{C} 5$ \\
\hline Supportive behavior & $\mathrm{C} 6$ \\
\hline Personnel empowerment & $\mathrm{C} 7$ \\
\hline Trustful climate & $\mathrm{C} 8$ \\
\hline Teamwork spirit & $\mathrm{C} 9$ \\
\hline human and social skills & $\mathrm{C} 10$ \\
\hline Decision-making power & $\mathrm{C} 11$ \\
\hline Stimulating and motivating people in the organization & $\mathrm{C} 12$ \\
\hline Professional commitment and responsibility & $\mathrm{C} 13$ \\
\hline
\end{tabular}

$(1,1,1) \otimes(1.23,1.73,2.26) \otimes(2.08,2.59,3.14) \otimes(1.23,1.66,2.08) \otimes(2.26,2.94,3.56))$

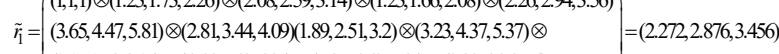


where, the triangular fuzzy number $(1.23,1.73,2.26)$ is fuzzy value of the first criterion versus the second criterion and the triangular fuzzy number $(2.2727,2.876,3.456)$ is fuzzy value of the first criterion versus the other twelve criteria (Table III).

Then, fuzzy weights of criteria are determined as follows:

$\tilde{w}_{i}=\tilde{r}_{i} \otimes\left(\tilde{r}_{1} \oplus \tilde{r}_{2} \oplus \tilde{r}_{3} \oplus \tilde{r}_{4} \oplus \tilde{r}_{5} \oplus \tilde{r}_{6} \oplus \tilde{r}_{7} \oplus \tilde{r}_{8} \oplus \tilde{r}_{9} \oplus \tilde{r}_{10} \oplus \tilde{r}_{11} \oplus \tilde{r}_{12} \oplus \tilde{r}_{13}\right)^{-1}$

Value of each criterion is multiplied by the inverse fuzzy sum of values. For example, fuzzy weight of the first criterion is determined as follows:

$\tilde{w}_{1}=\tilde{r}_{1} \otimes\left(\tilde{r}_{1} \oplus \tilde{r}_{2} \oplus \tilde{r}_{3} \oplus \tilde{r}_{4} \oplus \tilde{r}_{5} \oplus \tilde{r}_{6} \oplus \tilde{r}_{7} \oplus \tilde{r}_{8} \oplus \tilde{r}_{9} \oplus \tilde{r}_{10} \oplus \tilde{r}_{11} \oplus \tilde{r}_{12} \oplus \tilde{r}_{13}\right)^{-1}$

Fuzzy weight of the first criterion is $(0.118,0.185,0.28)$. Fuzzy weights are listed in Table IV.

TABLE III. FUZZY VALUE OF PAIRWISE COMPARISONS OF BEHAVIORAL MATURITY CRITERIA

\begin{tabular}{|c|c|c|c|}
\hline$\tilde{r}_{i}$ & $l \tilde{r}_{i}$ & $m \tilde{r}_{i}$ & $u \tilde{r}_{i}$ \\
\hline$\tilde{r}$ & 2.272 & 2.876 & 3.456 \\
\hline$\tilde{r}$ & 1.454 & 1.847 & 2.271 \\
\hline$\tilde{r}$ & 0.879 & 1.091 & 1.355 \\
\hline$\tilde{r}$ & 01.455 & 1.878 & 2.376 \\
\hline$\tilde{r}$ & 0.864 & 1.094 & 1.364 \\
\hline$\tilde{r}$ & 0.511 & 0.641 & 0.816 \\
\hline$\tilde{r}$ & 0.608 & 0.752 & 0.935 \\
\hline$\tilde{r}$ & 0.943 & 1.183 & 1.492 \\
\hline$\tilde{r}$ & 0.582 & 0.721 & 0.894 \\
\hline$\tilde{r}$ & 1.589 & 1.993 & 2.431 \\
\hline$\tilde{r}$ & 0.383 & 0.472 & 0.607 \\
\hline$\tilde{r}$ & 0.271 & 0.326 & 0.405 \\
\hline$\tilde{r}$ & 0.526 & 0.654 & 0.836 \\
\hline
\end{tabular}

TABLE IV. FUZZY WEIGHTS OF BEHAVIORAL MATURITY CRITERIA

\begin{tabular}{|c|c|c|c|c|c|}
\hline$\widetilde{W}_{j}$ & $l w_{j}$ & $m w_{j}$ & $u W_{j}$ & Defuzzified weight & Rank \\
\hline$\widetilde{W}_{1}$ & 0.118 & 0.185 & 0.28 & 0.189 & 1 \\
\hline$\widetilde{W}_{2}$ & 0.076 & 0.119 & 0.184 & 0.12 .26 & 4 \\
\hline$\widetilde{W}_{3}$ & 0.046 & 0.07 & 0.11 & 0.072 & 6 \\
\hline$\widetilde{W}_{4}$ & 0.076 & 0.121 & 0.192 & 0.12 .53 & 3 \\
\hline$\widetilde{W}_{5}$ & 0.045 & 0.07 & 0.11 & 0.071 & 7 \\
\hline$\widetilde{W}_{6}$ & 0.026 & 0.041 & 0.066 & 0.042 & 11 \\
\hline$\widetilde{W}_{7}$ & 0.032 & 0.048 & 0.076 & 0.049 & 8 \\
\hline$\widetilde{W}_{8}$ & 0.049 & 0.076 & 0.121 & 0.079 & 5 \\
\hline$\widetilde{W}_{9}$ & 0.03 & 0.046 & 0.072 & 0.047 & 9 \\
\hline$\widetilde{W}_{10}$ & 0.083 & 0.128 & 0.197 & 0.132 & 2 \\
\hline$\widetilde{W}_{11}$ & 0.02 & 0.03 & 0.049 & 0.028 & 12 \\
\hline$\widetilde{W}_{12}$ & 0.014 & 0.021 & 0.033 & 0.021 & 13 \\
\hline$\widetilde{W}_{13}$ & 0.027 & 0.042 & 0.068 & 0.043 & 10 \\
\hline & & & & & \\
\hline
\end{tabular}

As shown, the top five priorities include transformational leadership (0.189), human and social skills (0.132), knowledge orientation and organizational knowledge $(0.12 .53)$, emotional intelligence of managers (0.12.26) and trustful climate (0.079), respectively.

\section{Conceptual Model Testing}

Structural equation modeling (SEM) was used to analyze the conceptual model using the software Smart PLS. The structural model is reported below. T-values were used to analyze significance of the relationships; the Figures 1 and Figure 2 report $t$-values for structural relationships and measurement.

\section{Hypothesis Testing}

This section tests hypotheses by $\beta$-values and t-values. Tvalues $>1.96$ indicate significant path; thus, the hypothesis is accepted $(\alpha=0.05)$. Table 5 reports t-test results.

Based on PLS outputs, hypotheses are tested as follows:

- Hypothesis 1: Personnel empowerment as an aspect of behavioral maturity is effective on KM establishment. $\mathrm{T}=5.533(>|1.96|)$ indicates that hypothesis 1 is confirmed at 0.99 confidence. Thus, personnel empowerment as an aspect of behavioral maturity is effective on $\mathrm{KM}$ establishment. Moreover, $\beta=0.199$ indicates direct and positive effect of personnel empowerment on KM establishment.word "data"

- Hypothesis 2: training courses for managers as an aspect of behavioral maturity is effective on KM establishment. $\mathrm{T}=4.155(>|1.96|)$ indicates that hypothesis 2 is confirmed at 0.99 confidence. Thus, training courses for managers as an aspect of behavioral maturity is effective on KM establishment. Moreover, $\beta=0.356$ indicates direct and positive effect of training courses for managers on $\mathrm{KM}$ establishment.

- Hypothesis 3: teamwork spirit as an aspect of behavioral maturity is effective on $\mathrm{KM}$ establishment. $\mathrm{T}=3.181$ $(>|1.96|)$ indicates that hypothesis 3 is confirmed at 0.99 confidence. Thus, teamwork spirit as an aspect of behavioral maturity is effective on $\mathrm{KM}$ establishment. Moreover, $\beta=0.194$ indicates direct and positive effect of teamwork spirit on KM establishment.

- Hypothesis 4: decision-making power as an aspect of behavioral maturity is effective on $\mathrm{KM}$ establishment. $\mathrm{T}=2.009(>|1.96|)$ indicates that hypothesis 4 is confirmed at 0.99 confidence. Thus, decision-making power as an aspect of behavioral maturity is effective on $\mathrm{KM}$ establishment. Moreover, $\beta=0.122$ indicates direct and positive effect of decision-making power on KM establishment.

- Hypothesis 5: human and social skill as an aspect of behavioral maturity is effective on $\mathrm{KM}$ establishment. $\mathrm{T}=5.390(>|1.96|)$ indicates that hypothesis 5 is confirmed at 0.99 confidence. Thus, human and social skill as an aspect of behavioral maturity is effective on KM establishment. Moreover, $\beta=0.288$ indicates direct and positive effect of human and social skills on KM establishment. 


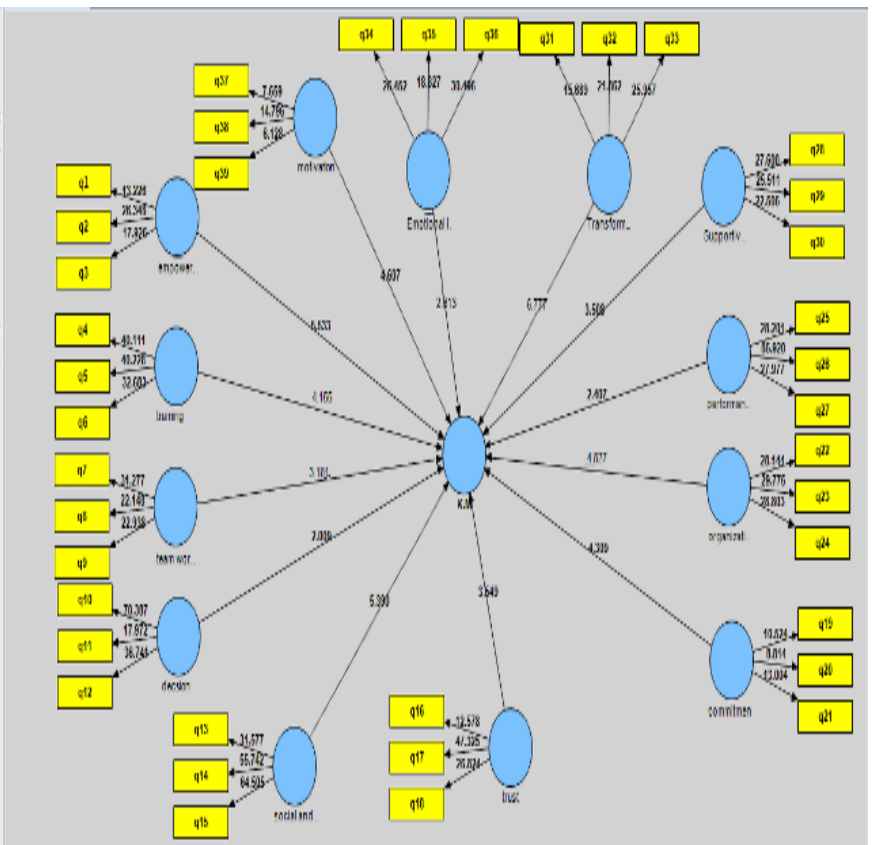

Fig. 1. PLS model for estimates of significance

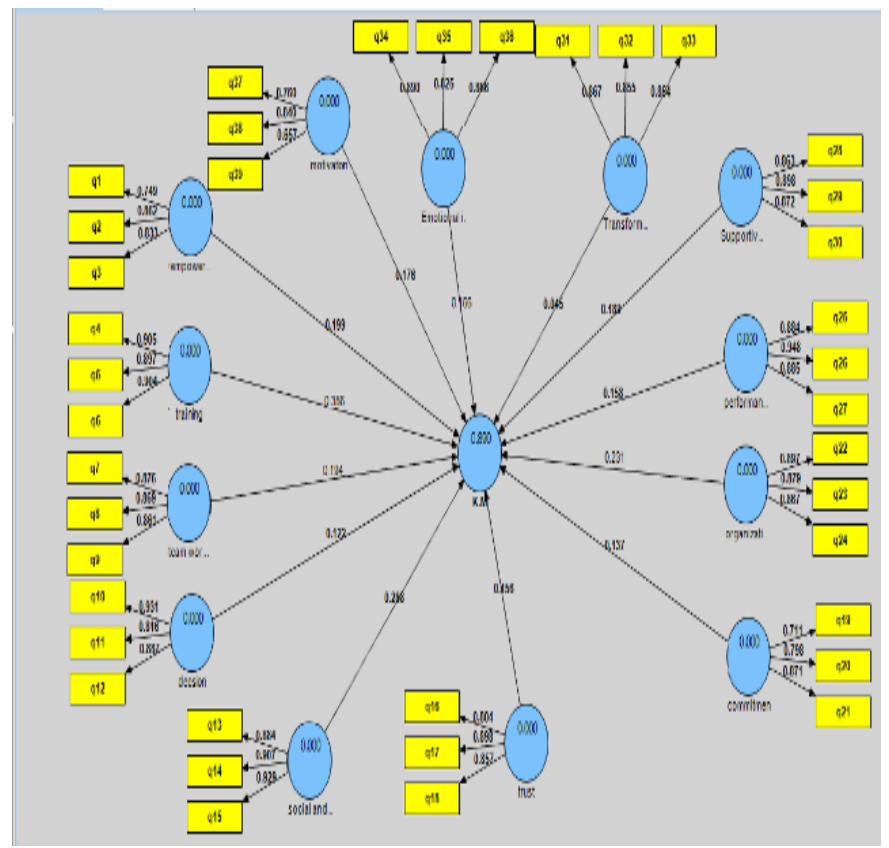

Fig. 2. PLS model for standardized estimates

- Hypothesis 6: trustful climate as an aspect of behavioral maturity is effective on $\mathrm{KM}$ establishment. $\mathrm{T}=3.549$ $(>|1.96|)$ indicates that hypothesis 6 is confirmed at 0.99 confidence. Thus, trustful climate as an aspect of behavioral maturity is effective on KM establishment. Moreover, $\beta=0.156$ indicates direct and positive effect of trustful climate on KM establishment.
- Hypothesis 7: professional commitment and responsibility as an aspect of behavioral maturity is effective on $\mathrm{KM}$ establishment. $\mathrm{T}=4.309(>|1.96|)$ indicates that hypothesis 7 is confirmed at 0.99 confidence. Thus, professional commitment and responsibility as an aspect of behavioral maturity is effective on KM establishment. Moreover, $\beta=0.137$ indicates direct and positive effect of professional commitment and responsibility on KM establishment.

- Hypothesis 8: knowledge orientation and organizational knowledge as an aspect of behavioral maturity is effective on $\mathrm{KM}$ establishment. $\mathrm{T}=4.827(>|1.96|)$ indicates that hypothesis 8 is confirmed at 0.99 confidence. Thus, knowledge orientation and organizational knowledge as an aspect of behavioral maturity is effective on KM establishment. Moreover, $\beta=0.231$ indicates direct and positive effect of knowledge orientation and organizational knowledge on KM establishment.

- Hypothesis 9: quantitative management as an aspect of behavioral maturity is effective on $\mathrm{KM}$ establishment. $\mathrm{T}=2.407(>|1.96|)$ indicates that hypothesis 9 is confirmed at 0.95 confidence. Thus, quantitative management as an aspect of behavioral maturity is effective on $\mathrm{KM}$ establishment. Moreover, $\beta=0.158$ indicates direct and positive effect of quantitative management on $\mathrm{KM}$ establishment.

- Hypothesis 10: supportive behavior as an aspect of behavioral maturity is effective on $\mathrm{KM}$ establishment. $\mathrm{T}=3.508(>|1.96|)$ indicates that hypothesis 10 is confirmed at 0.99 confidence. Thus, supportive behavior as an aspect of behavioral maturity is effective on KM establishment. Moreover, $\beta=0.189$ indicates direct and positive effect of supportive behavior on KM establishment.

- Hypothesis 11: transformational leadership as an aspect of behavioral maturity is effective on $\mathrm{KM}$ establishment. $\mathrm{T}=6.770(>|1.96|)$ indicates that hypothesis 11 is confirmed at 0.99 confidence. Thus, transformational leadership as an aspect of behavioral maturity is effective on $\mathrm{KM}$ establishment. Moreover, $\beta=0.045$ indicates direct and positive effect of transformational leadership on $\mathrm{KM}$ establishment.

- Hypothesis 12: emotional intelligence as an aspect of behavioral maturity is effective on $\mathrm{KM}$ establishment. $\mathrm{T}=2.613(>|1.96|)$ indicates that hypothesis 12 is confirmed at 0.99 confidence. Thus, emotional intelligence as an aspect of behavioral maturity is effective on $\mathrm{KM}$ establishment. Moreover, $\beta=0.166$ indicates direct and positive effect of emotional intelligence on $\mathrm{KM}$ establishment.

- Hypothesis 13: stimulation and motivation of organizational people as an aspect of behavioral maturity is effective on KM establishment. T=4.607 ( $>|1.96|)$ indicates that hypothesis 13 is confirmed at 0.99 confidence. Thus, stimulation and motivation of organizational people as an aspect of behavioral maturity is effective on $\mathrm{KM}$ establishment. Moreover, $\beta=0.176$ indicates direct and 
positive effect of stimulation and motivation of organizational people on KM establishment.

TABLE V. T-TEST RESULTS; HYPOTHESIS TESTING

\begin{tabular}{|c|c|c|c|c|c|}
\hline \multirow{2}{*}{ Hypothesis } & \multicolumn{2}{|c|}{ Variable } & \multirow{2}{*}{$\begin{array}{c}\boldsymbol{\beta}- \\
\text { value }\end{array}$} & \multirow{2}{*}{$\begin{array}{c}\mathrm{t}- \\
\text { value }\end{array}$} & \multirow{2}{*}{ Result } \\
\hline & Independent & Dependent & & & \\
\hline 1 & $\begin{array}{c}\text { Personnel } \\
\text { empowerment }\end{array}$ & $\begin{array}{c}\text { KM } \\
\text { establishment }\end{array}$ & 0.199 & 5.533 & Accepted \\
\hline 2 & $\begin{array}{l}\text { Training courses } \\
\text { for managers }\end{array}$ & $\begin{array}{c}\text { KM } \\
\text { establishment }\end{array}$ & 0.356 & 4.155 & Accepted \\
\hline 3 & Teamwork spirit & $\begin{array}{c}\text { KM } \\
\text { establishment }\end{array}$ & 0.194 & 3.181 & Accepted \\
\hline 4 & $\begin{array}{c}\text { Decision making } \\
\text { power }\end{array}$ & $\begin{array}{c}\text { KM } \\
\text { establishment }\end{array}$ & 0.122 & 2.009 & Accepted \\
\hline 5 & $\begin{array}{l}\text { Human and } \\
\text { social skills }\end{array}$ & $\begin{array}{c}\text { KM } \\
\text { establishment }\end{array}$ & 0.288 & 5.390 & Accepted \\
\hline 6 & Trustful climate & $\begin{array}{c}\text { KM } \\
\text { establishment }\end{array}$ & 0.156 & 3.549 & Accepted \\
\hline 7 & $\begin{array}{l}\text { Commitment } \\
\text { and } \\
\text { responsibility }\end{array}$ & $\begin{array}{c}\text { KM } \\
\text { establishment }\end{array}$ & 0.137 & 4.309 & Accepted \\
\hline 8 & $\begin{array}{l}\text { Knowledge } \\
\text { orientation }\end{array}$ & $\begin{array}{c}\text { KM } \\
\text { establishment }\end{array}$ & 0.231 & 4.827 & Accepted \\
\hline 9 & $\begin{array}{l}\text { Quantitative } \\
\text { management }\end{array}$ & $\begin{array}{c}\text { KM } \\
\text { establishment }\end{array}$ & 0.158 & 2.407 & Accepted \\
\hline 10 & $\begin{array}{c}\text { Supportive } \\
\text { environment }\end{array}$ & $\begin{array}{c}\text { KM } \\
\text { establishment }\end{array}$ & 0.189 & 3.508 & Accepted \\
\hline 11 & $\begin{array}{c}\text { Transformational } \\
\text { leadership }\end{array}$ & $\begin{array}{c}\text { KM } \\
\text { establishment }\end{array}$ & 0.045 & 6.77 & Accepted \\
\hline 12 & $\begin{array}{c}\text { Emotional } \\
\text { intelligence }\end{array}$ & $\begin{array}{c}\text { KM } \\
\text { establishment }\end{array}$ & 0.166 & 2.613 & Accepted \\
\hline 13 & $\begin{array}{c}\text { Stimulation and } \\
\text { motivation }\end{array}$ & $\begin{array}{c}\text { KM } \\
\text { establishment }\end{array}$ & 0.176 & 4.607 & Accepted \\
\hline
\end{tabular}

These findings are consistent with [8, 21-26] who identified a part of effective variables on behavioral maturity. For example, in [21] authors identified feedback and participatory culture as effective factors on maturity of human resources. In [22], authors noted personnel attitude as an important factor in maturity of employees and managers in knowledge management, while they identified pessimism and organizational silence as destructive factors in $\mathrm{KM}$ establishment; this study identified these factors in a wider framework. Moreover, in [23], the author identified participatory culture, trustful climate, feedback, transformational leadership, organizational intelligence and spirituality as effective factors on behavioral maturity of employees and managers, which is partially consistent with the current study. In [26], the author identified objective trainings, performance evaluation and meritocracy as the most important measures in maturity of human resources in establishing knowledge management.

\section{CONCLUSION}

Three steps were used to identify the effective factors on behavioral maturity of managers in establishing knowledge management. In the first step, the author identified a number of criteria based on theoretical background and literature review. Then, the author used interviews with experts to identify some other factors effective on behavioral maturity of managers in establishing knowledge management. Thirty-four criteria were identified in this step. The author used screening for consensus of experts. The identified criteria were weighted by 20 experts. According to the experts, the importance of 13 criteria was higher than average. Fuzzy AHP was used to obtain importance of variables. By pairwise comparison of variables by insurance and academic experts, the author weighted the variables. According to the results, the top five priorities included transformational leadership (0.189), human and social skills $(0.132)$, knowledge orientation and organizational knowledge (0.12.53), emotional intelligence of managers $(0.12 .26)$ and trustful climate (0.079), respectively. As the results showed, behavioral maturity of managers was higher than average for $\mathrm{KM}$ establishment; this indicates good maturity of managers in $\mathrm{KM}$ establishment. T-test results showed that the mean behavioral maturity was higher than 3 (3.415-3.882), indicating relatively high importance of behavioral maturity among managers of Iran Insurance Company. This suggests that managers of Iran Insurance Company are well aware of the importance of KM establishment in their organization and support this effectively. As the results showed, training courses for managers, personnel empowerment and transformational leadership are highly important; thus, top management of Iran Insurance Company is recommended to make efforts to improve behaviors, job awareness and career path of employees and managers to direct them in a predetermined framework and foster them based on specified factors.

\section{REFERENCES}

[1] H. R. Rezvani, Strategic knowledge management, Mazandaran University Publication, Mazandran, Iran, 2012

[2] M. Allegra, D. La Guardia, S. Ottaviano, V. Dal Grande, M. Gentile, "A serious game to promote and facilitate entrepreneurship education for young students", International Conference on Education and Educational Technologies, pp. 256-263, July 16, 2013

[3] N. Dehghan, F. Dehghan, S. Fathi, "Explanation and testing of interaction between learning capabilities", Innovation And Sustainable Competitive Advantage, Strategic Management Studies, Vol. 9, No. 1, pp. 128-150, 2012

[4] G. Tabarsa, A. Rezaeian, P. Nazari, H. Amir, "Yompetitive advantage model based on organizational intelligence in knowledge-based organizations", New Marketing Pesearch, Vol. 2, No. 4, pp. 47-72, 2012

[5] V. B. Korado, M. I. Ramos, "The impact of knowledge management on organizational performance", Economic and Business Review for Central and South-Eastern Europe, Vol. 14, No. 2, pp. 146-147, 2010

[6] B. Hamzei, "A framework for design and implementation of knowledge management systems", Knowledge Management, Vol. 1, No. 1, pp. 200202, 2012

[7] M. Aje, "Dynamic capabilities: what are they?", Journal of Strategic Management, Vol. 21, No. 5, pp. 21-105, 2005

[8] P. Akhavan, M. Jafari, "Re-engineering in organization", Journal of Tadbir, Vol. 14, No. 5, pp. 12-23, 2006.

[9] G. W. Chen, R. W. Zmud, Y. G. Kim, J. N. Lee, "Behavioural Intention Formation in Knowledge Sharing: Examining the Roles of Extrinsic Motivators, Social-Psychological Froces, and Organizational Climate", MIS Quarteriy, Vol. 29, No. 1, pp. 1-26, 2005

[10] J. Y. Chang, J. Y. Hsu, T. L. Chou, "State strategy and industrial socioeconomic practices in Taipei's international trade fairs", Temporary Knowledge Ecologies: The Rise of Trade Fairs in the Asia-Pacific Region, Vol. 29, No. 1, pp. 234-235, 2015

[11] D. R. Comer, G. Vega, "Moral courage in organizations: Doing the right thing at work", ME Sharpe, 2015 
[12] P. Ritala, H. Olander, S. Michailova, K. Husted, "Knowledge sharing, knowledge leaking and relative innovation performance: An empirical study", Technovation, Vol. 31, No. 35, pp. 22-31, 2015

[13] M. J. Donate, J. D. de Pablo, "The role of knowledge-oriented leadership in knowledge management practices and innovation", Journal of Business Research, Vol. 68, No. 2, pp. 360-70, 2015

[14] H. Ghalei, M. Mohajerani, "Attitudes towards the implementation of elearning faculty members at the University of Medical Sciences", Urmia Medical Journal,Vol. 25, No. 6, pp. 20-36, 2014

[15] M. Ahmadi, A. Asgari, "Studied the infrastructures required for establishing knowledge management in universities", Strategic Management Studies, Vol. 4, No. 2, pp. 20-25, 2015

[16] M. Sabzalipour, "Determined the effect of knowledge management establishment on organizational excellence", Management Conference, Vol. 5, No. 6, pp. 4-10, 2014

[17] A. Noruzy, V. M. Dalfard, B. Azhdari, S. Nazari-Shirkouhi, A. Rezazadeh, "Relations between transformational leadership, organizational learning, knowledge management, organizational innovation, and organizational performance: an empirical investigation of manufacturing firms", The International Journal of Advanced Manufacturing Technology,Vol. 64, No. 8, pp. 1037-1085, 2013

[18] A. Calvo-Mora, A. Navarro-García, R. Periañez-Cristobal, "Project to improve knowledge management and key business results through the EFQM excellence model", International Journal of Project Management, Vol. 33, No. 8, pp. 1638-1651, 2015
[19] I. L. Wu, J. L. Chen, J.L., "Knowledge management driven firm performance: The roles of business process capabilities and organizational learning", Journal of Knowledge Management, Vol. 18, No. 6, pp. 1141-1164, 2014

[20] C. Fornell, D. F. Larcker, "Structural equation models with unobservable variables and measurement error: Algebra and statistics", Journal of Marketing Research, pp. 382-388, 1981

[21] C. Y. Hung, S. Ming Hung, Q. Pin Lin, M. L. Tsai, "Critical Factors In Adopting a Knowledge Management System For The Pharmaceutical Industry", Industrial Management \& Data Systems, Vol. 105, No. 2, pp. 164-183, 2005

[22] R. E. Rhodes, G. Nasuti, "Trends and changes in research on the psychology of physical activity across 20years-A quantitative analysis of 10 journals" Preventive Medicine, Vol. 53, No. 1, pp. 17-23, 2011

[23] J. Stewart, "Technology in Spiritual Transformation", Global Missiology English, Vol. 1, No. 5, pp. 38-51, 2010

[24] A. Monavvarian, Z. Khamda, "Towards successful knowledge management: People development approach", Business Strategy Series, Vol. 11, No. 1, pp. 20-42, 2010

[25] H. Zaim, E. Tatoglu, S. Zaim, "Performance of knowledge management practices: a causal analysis", Journal of Knowledge Management, Vol. 11, No.6, pp. 54-67, 2012

[26] M. Yeng, "Critical success factors for implementing knowledge management in small and medium enterprises", Industrial management \& Data systems, Vol. 105, No. 3, pp. 261-279, 2012 